\title{
Cervical lymph node FNAC: a simple and sensitive tool to diagnosis malignancies
}

\author{
Shah M. G. ${ }^{1}$, Goel D. K. ${ }^{2}$, Patel T. S. ${ }^{3}$, Trivedi P. P. ${ }^{4}$ \\ ${ }^{1}$ Dr. Majal G. Shah, Assistant Professor, ${ }^{2}$ Dr. Deepak K. Goel, Resident Doctor, ${ }^{3}$ Dr. Trupti S. Patel Associate Professor, \\ ${ }^{4}$ Dr. Priti P. Trivedi, Professor and Head of the Department; all authors are attached with Department of Pathology, Gujarat \\ Cancer Research Institute, Ahmedabad, Gujarat, India.
}

Corresponding Author: Dr. Deepak K. Goel, Resident Doctor, Department of Pathology, Gujarat Cancer Research Institute, Ahmedabad, Gujarat, India. E-mail: drdpkgoel@gmail.com

\begin{abstract}
Introduction: Fine needle aspiration cytology (FNAC) of a lymph node is a simple screening and diagnostic tool to diagnose malignancies both primary as well as secondary which not only confirms the presence of metastatic disease, but also suggests regarding the nature and origin of the primary tumour. It is a well-tolerated, cost effective, almost free of complication procedure and reproducible which helps to diagnose and monitor the recurrence of malignancies. Aim: To assess the various malignant causes of cervical lymphadenopathy through FNAC. Design: A retrospective record based cross-sectional study of 125 patients with enlarged cervical lymph nodes diagnosed to have primary or secondary lymph node malignancy by cytology and confirmed by histopathology and immunohistochemistry wherever required. Materials and Methods: The material was obtained from patients, having enlarged cervical neck node over a period of one year in cytology laboratory of the Department of Pathology, Gujarat cancer research institute. Cervical lymph nodes were aspirated, and smears were prepared \& processed following standard techniques. Data was collected, tabulated and then analysed. Results: In this study,125 cases of cervical lymphadenopathy were analysed. Male were affected much more commonly than females in the ratio of approximately 9:1. The most common age of presentation was fifth and the sixth decade. Most common malignancy to be diagnosed was squamous cell carcinoma. Most common primary site was oral cavity. Conclusion: FNAC is a quick, convenient and safe method for diagnosis of suspected / unsuspected metastatic and recurrence of malignancy in neck nodes.
\end{abstract}

Keywords: Fine needle aspiration cytology, Cervical lymph node, Malignancy

\section{Introduction}

Lymphadenopathy is a very common finding encountered by clinicians. Cervical Lymphadenopathy is usually defined as cervical nodal tissue measuring more than $1 \mathrm{~cm}$ in diameter which could be variety of disease ranging from innocuous reactive lesion from mild infections to granulomas to metastatic malignancies.

Based on the duration, cervical lymphadenopathy is further classified into acute lymphadenopathy (2 weeks duration), subacute lymphadenopathy (2-6 weeks duration), and chronic lymphadenopathy is considered in any lymphadenopathy that does not resolve by 6 weeks As management of each cause demands a separate approach, hence, determination of cause of enlarged lymph nodes cannot be overemphasized. Cervical lymph nodes are a common site of metastasis

Manuscript received: $20^{\text {th }}$ July 2019

Reviewed: $30^{\text {th }}$ July 2019

Author Corrected: $6^{\text {th }}$ August 2019

Accepted for Publication: 12 ${ }^{\text {th }}$ August 2019 of various neoplastic lesions and a centre of lymphomas both Hodgkin's as well as non-Hodgkin's. These are easily accessible for FNAC, hence FNAC becomes an important diagnostic tool for cervical lymphadenopathies. Though biopsy is always considered as the gold standard, but it is more resource intensive, require anaesthesia, strict asepsis facilities and can leave a scar, hence FNAC is preferred over biopsy [1].

However, pathologist should always go for biopsy in doubtful or suspicious cases encountered on FNAC for confirmation.

This study is undertaken to highlight the role of FNAC of cervical lymph nodes in the diagnosis of suspected / unsuspected and recurrence of malignancies.

It helps to find out the frequency and aetiology of various primary as well as metastatic malignancies affecting cervical lymph nodes. 


\section{Material and Methods}

This is a hospital record based cross sectional retrospective study of 125 patients done in the department of Cytology, Gujarat cancer research institute, Ahmedabad.

Inclusion Criterion: It included all the patients of any age group with enlarged cervical lymph nodes with suspected malignancy who attended the hospital in a period of one year.

Exclusion criterion: Cases who had been already diagnosed with primary/metastatic malignancy in cervical nodes and have come for follow up FNAC after taking chemotherapy or radiotherapy.

Before the FNAC procedure, relevant clinical history, clinical examination, tumour marker and radiological investigations was done. Cervical lymph nodes were aspirated by using a $22 \mathrm{G} \times 1$ " needle attached to a $10 \mathrm{ml}$ disposable syringe. The aspirated material was expressed on to slides. Subsequently it is fixed with the help of methanol and smears were prepared, dried and stained with May-Grünwald Giemsa (MGG) stain \&
Original Research Article

Papanicolaou stain (PAP). In case of deep-seated lesions, Ultrasonography (USG) guided FNAC was performed. All the FNAC were reported under the following headings: - unsatisfactory- inadequate cellularity for proper interpretation, reactive - nonspecific inflammation and no atypical cell seen, suspicious-aspirates showing some cells with features of malignancy, where the material is not diagnostic of malignancy due to scanty, poorly preserved aspirates, malignant- presence of overtly malignant cells.

In cases where diagnosis of metastasis was given, and primary was unknown primary site was searched and confirmed by biopsy from primary site.

Special stains and immunohistochemical staining were done, wherever needed Lymph node biopsy was performed in doubtful cases and sections were stained with Haematoxylin-Eosin stain. The data was collected, analysed and tabulated.

Ethical considerations: Required ethical permission by the ethical committee of the institution was duly taken.

\section{Results}

The results from the present study are tabulated below

Table-1: Distribution of cytological diagnosis of cervical node FNAC.

\begin{tabular}{|c|c|c|c|}
\hline S No & Cytological diagnosis & No of cases & Percentage \\
\hline 2 & Unsatisfactory & 14 & $9.3 \%$ \\
\hline 4 & Reactive / Negative & 5 & $3.3 \%$ \\
\hline 3 & Suspicious & 6 & $4 \%$ \\
\hline 1 & Malignant & 125 & $83.3 \%$ \\
\hline & Total & $\mathbf{1 5 0}$ & $\mathbf{1 0 0} \%$ \\
\hline
\end{tabular}

Those cases which were clear cut malignant on FNAC were selected and followed up and rest of the analysis was done on these 125 cases

Distribution of cases based on gender: The male: female ratio in Cervical lymph node metastasis in the present study is 8:1 with 111 cases of male patients reported as compared to only 14 cases of female patients. It means that primary neoplasm causing cervical metastasis is much more common in males than females.

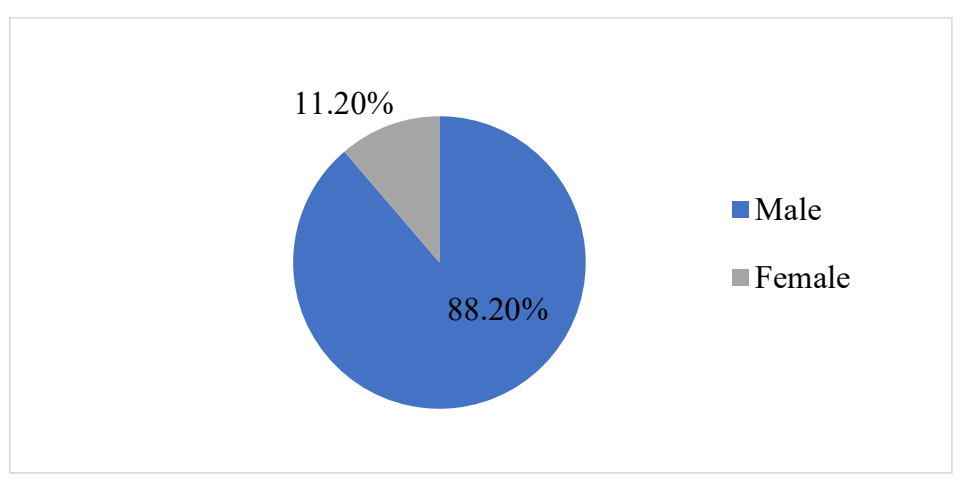

Figure 1: Distribution of cases based on gender. 


\section{Original Research Article}

Distribution of cases according to age: The maximum number of patients diagnosed with cervical lymph node metastasis were in fifth and sixth decade of their life followed by fourth decade and minimum in paediatric age group.

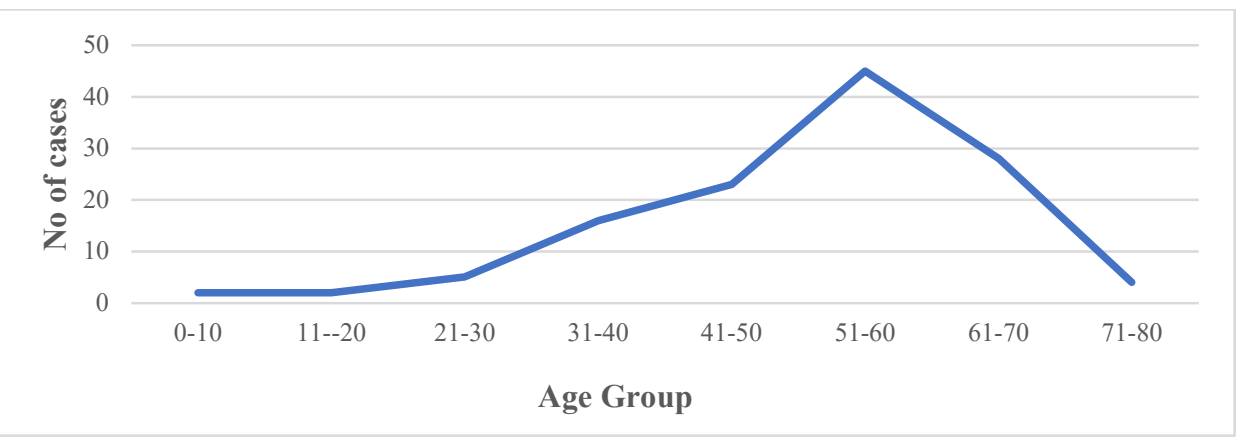

Figure 2: Distribution of cases according to age.

Table-2: Distribution of cases according to known/unknown primary site of origin

\begin{tabular}{|c|c|c|c|}
\hline S No. & Primary & No of cases & Percentage \\
\hline 1 & Known & 102 & $81.6 \%$ \\
\hline 2 & Unknown & 15 & $12 \%$ \\
\hline 3 & Haematological & 8 & $6.4 \%$ \\
\hline & Total & $\mathbf{1 2 5}$ & $\mathbf{1 0 0} \%$ \\
\hline
\end{tabular}

The ratio of known unknown primary site at time of FNAC is 7:1 with around 6 percent were separated as haematological malignancies.

Table-3: Distribution of cases with known primary site location wise and their correlation with their histological diagnosis confirmed by biopsy from the primary site.

\begin{tabular}{|c|c|c|c|c|}
\hline S No. & Site & No of cases & Histological diagnosis & Percentage \\
\hline 1 & Buccal mucosa & 39 & SCC (39) & $38.2 \%$ \\
\hline 2 & Larynx & 23 & SCC (23) & $22.5 \%$ \\
\hline 3 & Tongue & 16 & SCC (16) & $15.6 \%$ \\
\hline 4 & Nasopharyngeal & 5 & Nasopharyngeal carcinoma (5) & $4.9 \%$ \\
\hline 5 & Lip & 5 & SCC (5) & $4.9 \%$ \\
\hline 6 & Palate & 4 & SCC (4) & \multirow{2}{*}{$2.9 \%$} \\
\hline 7 & Oesophagus & 3 & SCC (2) & \multirow{2}{*}{$2.9 \%$} \\
\cline { 2 - 4 } & & & Adenocarcinoma (1) & $1.9 \%$ \\
\hline 8 & Thyroid & 3 & Papillary carcinoma of thyroid $(3)$ & $1.9 \%$ \\
\hline 10 & Breast & 2 & Invasive ductal carcinoma (2) & \multirow{2}{*}{$\mathbf{1 0 0} \%$} \\
\hline
\end{tabular}

Table depicted that buccal mucosa, larynx \& tongue are three most common site of tumour.

Table-4: Cytological diagnosis of cervical lymph node metastasis with known primary

\begin{tabular}{|c|c|c|c|}
\hline S No. & Type of cancer & No of cases & Percentage \\
\hline 1 & Squamous cell carcinoma & 82 & $80 . .3 \%$ \\
\hline 2 & Poorly differentiated & 7 & $6.8 \%$ \\
\hline 3 & Nasopharyngeal carcinoma & 5 & $4.9 \%$ \\
\hline 4 & Papillary thyroid carcinoma & 3 & $2.9 \%$ \\
\hline 5 & Invasive ductal carcinoma of breast & 2 & $1.9 \%$ \\
\hline 6 & Adenocarcinoma & 1 & $1.9 \%$ \\
\hline 7 & Small cell carcinoma & 102 & $0.9 \%$ \\
\hline & Total & $100 \%$ \\
\hline
\end{tabular}




\section{Original Research Article}

Table no 4 depicts about cytological diagnosis of lymph node metastasis and squamous cell carcinoma are the most common type of cancer observed.

Table-5: Cytological diagnosis of cervical lymph node metastasis with unknown primary site

\begin{tabular}{|c|c|c|c|}
\hline S No. & Type of cancer & No of cases & Percentage \\
\hline 1 & Squamous cell carcinoma & 9 & $60 \%$ \\
\hline 2 & Poorly differentiated carcinoma & 4 & $26.6 \%$ \\
\hline 3 & Adenocarcinoma & 2 & $13.4 \%$ \\
\hline & Total & 15 & $100 \%$ \\
\hline
\end{tabular}

Table no 5 depicts that in unknown primary site squamous cell cancer were most common followed by poorly differentiated carcinoma.

Table-6: Differential diagnosis of haematological malignancies. (diagnosed with help of immunohistochemistry)

\begin{tabular}{|c|c|c|c|c|}
\hline S No. & \multicolumn{2}{|c|}{ Haematological malignancy } & No of cases & Percentage \\
\hline \multirow[t]{5}{*}{1} & \multirow{5}{*}{$\begin{array}{l}\text { Non-Hodgkin's } \\
\text { Lymphoma (NHL) }\end{array}$} & $\mathrm{T}$ cell NHL (2) & \multirow[t]{5}{*}{6} & \multirow[t]{5}{*}{$75 \%$} \\
\hline & & Plasmablastic lymphoma (1) & & \\
\hline & & Large cell type (1) & & \\
\hline & & B cell NHL (1) & & \\
\hline & & Diffuse B cell (1) & & \\
\hline \multirow[t]{2}{*}{2} & \multicolumn{2}{|c|}{ Hodgkin's lymphoma } & 2 & $25 \%$ \\
\hline & \multicolumn{2}{|c|}{ Total } & 8 & $100 \%$ \\
\hline
\end{tabular}

\section{Discussion}

In the present study of 150 cases that presented with enlarged lymph nodes in our hospital in a period of six months, 125 cases were diagnosed to be malignant cytologically which is markedly high from other studies which have found the incidence to vary from 5.8 [1] to $25.03 \%$ [2-4]. Such a high percentage of malignancy does not show the actual frequency of malignancy as the cause of cervical lymphadenopathy, but it is due to the fact that our hospital is a tertiary cancer hospital and a referral centre for cancer in western India, hence, other on-malignant patients mostly get filtered out.

These malignancies were most common between the age group of 40-70 years of age. This is similar to the results obtained by Bhattacharjee et al [5] \& Mehrotra et al [6]

The sex ratio is heavily skewed towards the males (8:1). This is slightly more than other Indian studies undertaken by Mehrotra et al (3.8:1) [6] \& Bhattarcharjee et al (2.9:1) [5] \& differs from other foreign studies Engzell et al 1.07:1 [7] and Ustun et al 1:2 [8]. The widespread use of tobacco and cigarettes by Indian male population which is relatively less prevalent in females is the primary reason behind this discrepancy in the frequency of cancers. Also, in our country males are more likely to have easy and early access to health care than their counterparts.
All the cases with known primary have been confirmed with biopsy from the primary site. For about 12 percent of the cases primary site remained unknown even after the evaluation of the patients and mostly they were lost to follow up or even after extensive investigations no primary radiological evidence was available.

Cervical lymph nodes, particularly high jugular and posterior cervical nodes drain the head and neck and may harbour metastatic carcinomas originating in the nasopharynx, tonsillar fossa, tongue, floor of the mouth, thyroid, extrinsic larynx, facial skin, and scalp. The most common primary site of metastasis was oral cavity followed by the larynx, which was similar to the results obtained by Izhar. N. Bagwan et al [9] (oral cavity), Karabi Kohar et al [10](oral cavity), Malika Afroz et al [11] (larynx followed by oral cavity) Oral cavity including the buccal mucosa, palate and tongue and other adjoining areas like larynx and nasopharynx were the most common primary site of malignancy with cervical lymph node metastasis constituting up to $90 \%$. This data points towards the fact that head and neck region malignancies are the most common to get metastasized in the cervical lymph nodes and often they are diagnosed by the FNAC of the enlarged cervical lymph nodes. 


\section{Original Research Article}

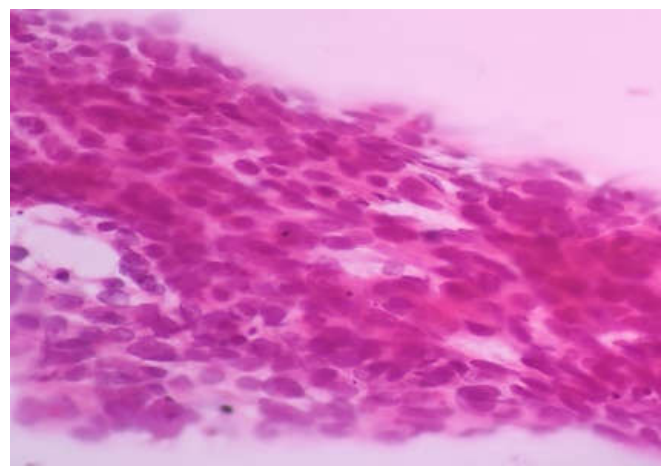

Fig 1a: Metastatic squamous cell carcinoma (40x, PAP stain),

The present study showed more cases of metastatic involvement of the lymph nodes (94\%) rather than lymphomas (6\%) ratio being 13:1. This was similar to other Indian studies $[12,13]$ although many variations have been noted depending upon the number of cases studied. Undoubtedly, Squamous cell carcinoma is the most common histological diagnosis done in the

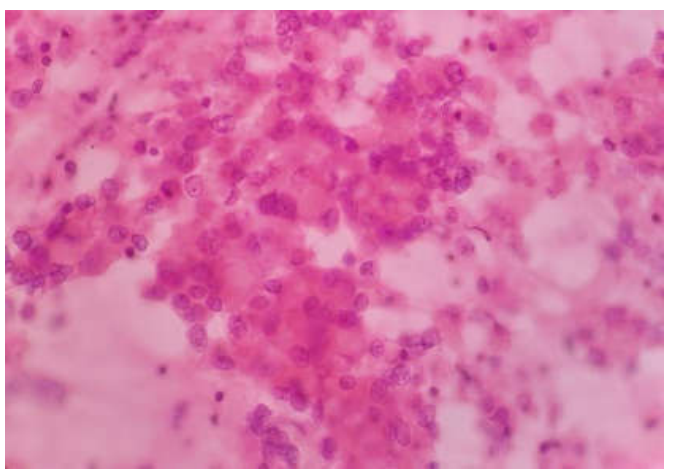

Fig 2b: Metastatic adenocarcinoma (40x, PAP stain)

metastatic cases of cervical lymphadenopathy which accounts for $73 \%$ of total malignancies. This is similar to the results obtained by the Kiran Alam et al [14] (squamous cell carcinoma) and Izhar. N. Bagwan et al [9] (squamous cell carcinoma), Ustun et al [8] (squamous cell carcinoma) and differ from the results of Chih Hsu et al [15] (Nasopharyngeal carcinoma).

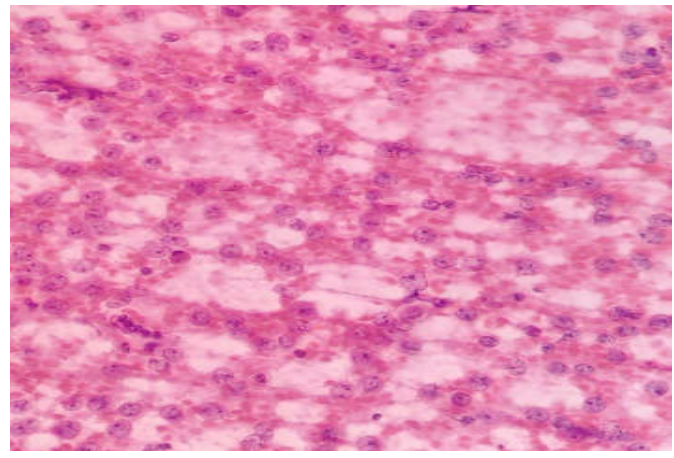

Figure-2: Diffuse Large B cell Lymphoma (100x, PAP stain)

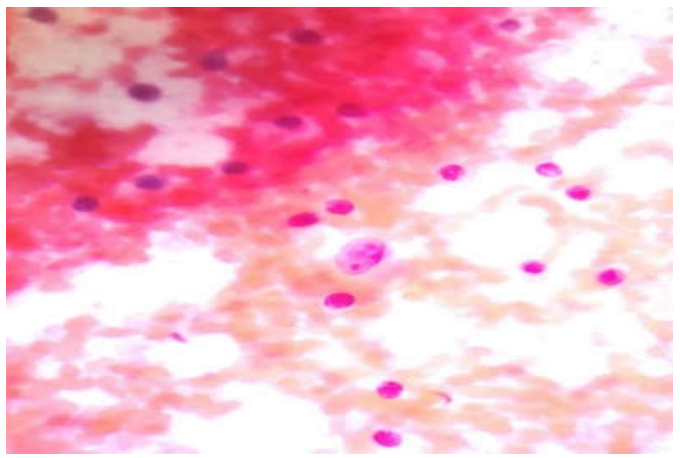

Figure-3: Hodgkins Lymphoma (100x PAP stain)

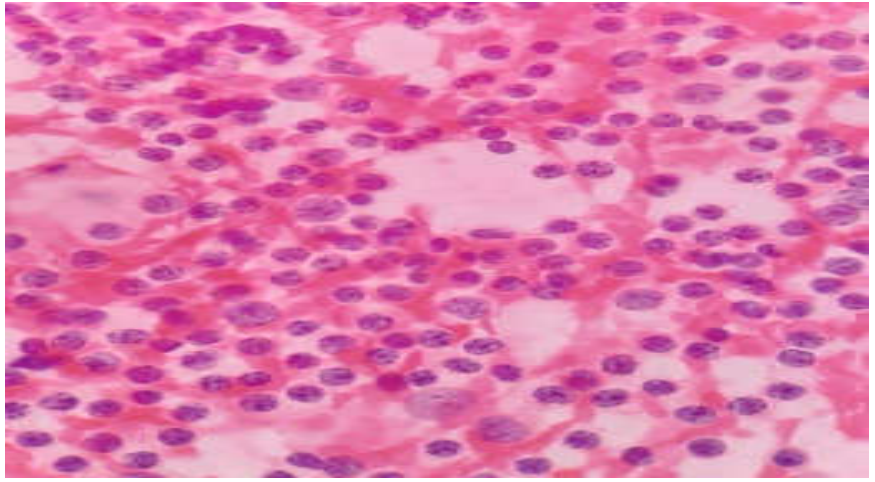

Figure-4: Non hodgkins lymphoma (100x, PAP stain)

This difference is due to the geographical variation between china and India. Nasopharyngeal carcinoma is endemic in china whereas it is much less common in India. Carcinomas of the nasopharynx and oropharynx are notorious for presenting with metastases in the cervical lymph nodes while the primary neoplasm remains unnoticeable All the haematological 


\section{Original Research Article}

malignancies diagnosed on cervical FNAC underwent cervical lymph node biopsy and immunohistochemistry to reach the final diagnosis.

\section{Conclusion}

FNAC of suspicious neck nodes is a safe \& easy procedure, which gives an accurate diagnosis in most of the cases. It is thus concluded that fine needle aspiration cytology is a quick, convenient method for diagnosis of suspected / unsuspected metastatic neck nodes.

The few diagnostic dilemmas can be largely overcome through careful clinical correlation followed by meticulous examination of the aspirates. FNAC of cervical lymph nodes is a very useful and simple tool in the diagnosis of lymph node malignancies. It may be the only tool in the diagnosis of metastatic lesions in the lymph nodes and can help to detect occult primary malignancies. For the diagnosis of lymphomas, it can suggest a preliminary diagnosis, which can be followed by histopathology and immuno-histochemistry for confirmation. Hence, the cytopathologist plays a vital role in the diagnosis of lymph node malignancies.

\section{What the study adds to the existing knowledge?}

The present study not only proves the importance of FNAC procedure in diagnosis of suspected / unsuspected and recurrence of malignancies but also it delineates the malignant aetiologies affecting the cervical lymph nodes in a large tertiary cancer care centre of western India. More such studies are required from different part of our country to know the full spectrum of diseases that can cause enlargement of cervical lymph nodes.

\section{Author's contribution}

Dr. Majal Shah: Concept, design, Definition of intellectual content, literature content, data acquisition, data analysis, statistical analysis, manuscript preparation, manuscript editing, manuscript review, guarantor.

Dr. Deepak Goel: Concept, design, Definition of intellectual content, literature content, data acquisition, data analysis, statistical analysis, manuscript preparation, manuscript editing, manuscript review, guarantor.

Dr. Trupti Patel: Definition of intellectual content, literature content, manuscript editing, manuscript review, guarantor.

Dr. Priti Trivedi: Definition of intellectual content, literature content, manuscript editing, manuscript review, guarantor.

\author{
Findings: Nil; Conflict of Interest: None initiated \\ Permission from IRB: Yes
}

\section{References}

1. Khajuria R, Goswami KC, Singh K, Dubey VK. Pattern of lymphadenopathy on fine needle aspiration cytology in Jammu. JK Sci. 2006;8(3):145-149.

2. Hirachand S, Lakhey M, Akhter J, Thapa B. Evaluation of fine needle aspiration cytology of lymph nodes in Kathmandu Medical College, Teaching hospital. Kathmandu Univ Med J (KUMJ). 2009;7 (26): 139-142.

3. Ahmad T, Naeem M, Ahmad S, Samad A, Nasir A. Fine needle aspiration cytology (FNAC) and neck swellings in the surgical outpatient. J Ayub Med Coll Abbottabad. 2008;20(3):30-32.

4. Paul PC, Goswami BK, Chakrabarti S, Giri A, Pramanik R. Fine needle aspiration cytology of lymph nodes-An institutional study of 1448 cases over a fiveyear period. J Cytol. 2004;21(4):187.

5. Bhattacharjee A, Chakraborty A, Purkaystha P. Prevalence of head and neck cancers in the north eastan institutional study. Indian Journal of Otolaryngology and Head and Neck Surgery. 2006; 58(1):15-19. doi: 10.1007/BF02907731

6. Mehrotra R, Singh M, Gupta RK, Singh M, Kapoor AK. Trends of prevalence and pathological spectrum of head and neck cancers in North India. Indian $\mathrm{J}$ Cancer. 2005; 42(2): 89-93. doi: 10.4103/0019-509X. 16698

7. Engzell U, Jakobsson PA, Sigurdson A, Zajicek J. Aspiration biopsy of metastatic carcinoma in lymph nodes of the neck. A review of 1101 consecutive cases. ActaOtolaryngol. 1971;72(1):138-147.doi:10.3109/ 000 16487109122466

8. Ustün M, Risberg B, Davidson B, Berner A. Cystic change in metastatic lymph nodes: a common diagnostic pitfall in fine-needle aspiration cytology. Diagn Cytopathol. 2002;27(6):387-392. doi:10.1002/dc. 10201

9. Bagwan IN, Kane SV, Chinoy RF. Cytologic evaluation of the enlarged neck nodes. FNAC utility in metastatic neck disease. Int J Pathol. 2007;6(2). 
10. Konar K, Ghosh S, Ghosh T, Bhattacharya S, Sanyal $\mathrm{S}$. Pitfalls in the cytodiagnosis of metastatic squamous cell carcinoma in the head and neck: A retrospective study. J Cytol. 2008;25(4):119-122.

11. Afroz, M., Akhtar, N., Siddiquee, B. Metastatic neck node - a clinical study of 60 cases. Bangladesh Journal of Otorhinolaryngol. 2009;15(1):26-30. doi: https://doi.org/10.3329/bjo.v15i1.4307

12. Alam K, Khan A, Siddiqui F, Jain A, Haider N, Maheshwari V. Fine needle aspiration cytology (FNAC), a handy tool for metastatic lymphadenopathy. Int $\mathrm{J}$ Pathol. 2010;10(2):1-7.

13. Khajuria R, Goswami KC, Singh K, Dubey VK. Pattern of lymphadenopathy on fine needle aspiration cytology in Jammu. JK Sci. 2006;8(3):145-149.
14. Alam K, Maheshwari V, Haider N, Siddiqui F, Jain A, Khan A. Fine needle aspiration cytology (FNAC), a handy tool for metastatic lymphadenopathy. Int J Pathol. 2009;10(2).

15. Hsu C, Leung BS, Lau SK, Sham JS, Choy D, Engzell U. Efficacy of fine-needle aspiration and sampling of lymph nodes in 1,484 chinese patients. Diagnostic Cytopathol. 1990; 6 (3): 154159.

16.H. Kumar, S.S. Chandanwale, C.R. Gore, A.C. Buc, V. H. Satav, P.M. PagaroRole of fine needle aspiration cytology in assessment of cervical lymphadenopathy. Med J DY Patil Univ.2013;6(4):400-404. doi: 10. 4103/ 0975-2870.118287

\section{How to cite this article?}

Shah M. G., Goel D. K, Patel T. S, Trivedi P. P. Cervical lymph node FNAC: a simple and sensitive tool to diagnosis malignancies. Trop J Path Micro 2019;5(9):656-662.doi:10.17511/jopm.2019.i09.07. 